\title{
A Conversational Intervention Focused on Perspective-Taking Ability for a Child with Autism Spectrum Disorder
}

\author{
Chie MiyaderA*
}

Faculty of Education, Chiba University, Japan

\begin{abstract}
Individuals with autism spectrum disorder (ASD) have difficulty communicating with others and maintaining natural conversations. The present study aimed to examine the effectiveness of an intervention focused on the perspective-taking (PT) ability of a child with ASD. This intervention targeted PT skills and was designed to encourage the participant to recognize his emotions, understand his mental states and those of the others, and learn a practical way of talking. The participant's discourse ability was assessed using Theory of Mind tasks, Interpersonal Reactivity Index (IRI), and conversational analysis at baseline, post-intervention, and follow-up. In the conversational analysis, we examined his utterances, focusing on their adjacency in relation to prior adult utterances, and his pragmatic skills. The results showed that his scores for empathic concern (EC) increased on the IRI, and his pragmatic skills improved after the intervention. Therefore, it was found that our intervention focused on PT ability had some effects on improving the discourse ability of a child with ASD.
\end{abstract}

Key Words: autism spectrum disorder, discourse ability, intervention, perspective-taking (PT), Interpersonal Reactivity Index (IRI)

\section{Introduction}

Language dysfunction in individuals with autism spectrum disorder (ASD) has been considered to be one of the disorder's key characteristics since it was first identified by Kanner (1943). Individuals with ASD who do not suffer intellectual disabilities often have various language deficits related to social communication, including social pragmatic problems, the unique use of language, and the literal interpretation of words. Notably, the elements of pragmatic functioning play a crucial role in interpersonal communication skills. Individuals with ASD have difficulties in communicating with others and maintaining natural conversations. Capps, Kehres, and Sigman (1998) found that children with ASD often failed to respond to questions and comments. Furthermore, they offered fewer new and relevant conversational contributions than children with other developmental

\footnotetext{
* Corresponding Author

Mailing Address: 1-33 Yayoicho, Chiba-shi, Chiba 263-8522, Japan

E-mail Address: miyadera@faculty.chiba-u.jp

Received March 19, 2019, Accepted December 12, 2020

DOI: $10.6033 /$ specialeducation.9.49
}

delays. Studies on conversations between adults with ASD and researchers have revealed that individuals with ASD demonstrated significant problems in discourse ability, particularly circulation and repetitiveness (Dobbinson, Perkins, \& Boucher, 1998; Inada \& Kamio, 2007). They tended to focus on a topic in which they were interested and often switched topics without any prior indication. A method to assess discourse ability was introduced and a scale to measure language pragmatic impairments in people with ASD developed by de Villiers, Ginsberg, Vaccarella, and Szatmari (2007). This is a useful scale for evaluating the changes in social impairments in the conversations of those with ASD.

The ability to maintain and develop a topic of discourse is an important aspect of communicative competence (Tager-Flusberg \& Anderson, 1991). Tager-Flusberg and Anderson (1991) investigated whether children with ASD and children with Down Syndrome between the ages of three and six years were able to respond in a contingent or topically relevant manner to their mothers' utterances as well as add new information to the topic of discourse. They analyzed four opportunities of spontaneous speech throughout one year and examined adjacency to an adult's preceding utterances and relevance to conver- 
sation topics as well as whether the children added new information. The results revealed that children with ASD were less contingent in their discourse than those with Down Syndrome and showed no developmental changes in their contingent discourse. In essence, the children with ASD did not present new information and expand the conversation.

One may ask why most individuals with ASD experience difficulties with conversation skills. Conversations comprise interactions between speakers and listeners. When people talk to each other, they often infer what the other is thinking. To keep the conversation flowing, they often guess what the other knows and wants to know. To enjoy a conversation, it is imperative that they understand the other's feelings about the topic. Because language competencies such as receptive vocabulary and literacy are strongly related to emotional knowledge (Beck, Kumschick, Eid, \& Klann-Delius, 2012), emotional competence is a significant factor when communicating with others. Since Baron-Cohen, Leslie, and Frith (1985) proposed that children with ASD lack theory of mind (ToM), it has been known that they have difficulty communicating with others because they are unable to recognize and understand others' emotions. ToM is an essential social cognitive skill, which encompasses the ability to think about the self and others' mental states, including thoughts, feelings, and desires. The development of ToM is related to discourse ability in children with ASD (Hale \& Tager-Flusberg, 2005). Hale and Tager-Flusberg (2005) investigated the developmental trajectory of discourse ability and ToM in 57 children between the ages of four and 13 years with ASD. They analyzed the language sample and battery of ToM tasks twice during the course of a year and demonstrated that ToM was linked to discourse ability in children with ASD. These studies have shown the relation between ToM and conversational skills in development. In addition, to maintain a conversation, it is important for individuals to understand their conversational partners' perspective and therefore, discourse ability is strongly related to individual levels of perspective-taking (PT) (Nilsen \& Fecica, 2011; Southall \& Campbell, 2015), which is the ability to see the world from others' point of view. Individuals with ASD have difficulty with $\mathrm{PT}$ in comparison to those without ASD (Hamilton, Brindley, \& Frith, 2009) and struggle to understand others' perspec- tives. The Interpersonal Reactivity Index (IRI: Davis, 1983) is a scale, which measures PT ability. Davis (1983) employed this scale to assess the tendency to adopt PT ability spontaneously. Research has shown that adults with ASD have significantly lower scores of PT in comparison to those without ASD (Rogers, Dziobek, Hassenstab, Wolf, \& Convit, 2007; Dziobek, Rogers, Fleck, Bahnemann, Heekeren, Wolf, \& Convit, 2008). Aichhorn, Perner, Kronbichler, Staffem, and Ladurner (2006) asserted that in individuals with ASD, PT as well as social cognition are linked with ToM. Accordingly, we postulated that in developing discourse ability, it is crucial to recognize one's own and others' perspectives accurately. Furthermore, both are essential factors for establishing conversation with another individual.

There are various important findings about training in conversational skills. Palmen, Didden, and Arts (2008) conducted small-group training on questionasking skills, which comprised verbal feedback and role-play during their tutorial conversations. They reported nine adolescents with ASD improved their question-asking skills during those conversations. Nuernberger, Ringdahl, Vargo, Crumpecker, and Gunnarsson (2013) employed a behavioral skills training package to teach three young adults with ASD conversational skills. The training package included delivering instructions, modeling appropriate conversation, and role-playing. The results revealed that the intervention was effective and led to an immediate improvement in conversational skills in a natural environment by employing temporal behavioral skills training, which comprised instructions, modeling, rehearsal, and feedback. Moreover, LeBlanc, Coates, Daneshvar, Charlop-Christy, Morris, and Lancaster (2003) demonstrated that modeling by video may be a useful strategy for teaching PT skills. Scattone (2007) showed that it was effective for children with ASD to employ self-monitoring in social skills training. In Japan, Kato and Fujino (2018) documented the efficacy of a table-talk role-playing game aimed at encouraging altruistic speech in those with ASD.

The purpose of the present study was to examine the effectiveness of an intervention that focused on the PT ability of a child with ASD. Although many studies have evaluated the effectiveness of conversational skills training for individuals with ASD, they have not explored improvement in PT ability. This intervention targeted PT skills and was designed 
to encourage the participant to recognize his emotions, understand his mental states and those of the others, and learn to talk in a practical way. In accordance with Nuernberger et al. (2013), we planned the intervention using behavioral skills training that comprised instructions, modeling, rehearsal, and feedback. The effects of the intervention were verified by conversation analysis of a free-talk scene and the measurement of empathy utilizing the IRI.

We hypothesized the intervention would have the following effects. First, after the intervention, the participant would pass the ToM tasks because he would be able to recognize his emotions and understand his mental states and those of others. Second, the IRI score, especially on the PT domain would be significantly higher as a result of the intervention that focused on PT ability. Third, the participant would have more adjacent utterances and utterances about new information than those with no new information in conversational analysis. Tager-Flusberg and Anderson (1991) noted that the increase of utterances about new information and adjacent utterances of a preceding topic indicates an improvement in discourse ability in a conversation. Finally, the participant's pragmatic skills scores would decrease and his pragmatic skills would improve.

\section{Method}

\section{Participant}

The participant was a nine-year-old Japanese boy with ASD. His full IQ (FIQ), verbal IQ (VIQ), and performance IQ (PIQ) scores were 111, 100, and 120, respectively. These fell within or above the average range of the third edition of the Wechsler Intelligence Scale for Children (WISC-III; Japanese WISC-III Publication Committee, 1998). His four index scores for verbal comprehension, perceptual organization, freedom from distractibility, and processing speed were $99,124,94$, and 108 , respectively. When he was nine years and six months old, he was unable to pass some of the ToM tasks, including the Sally-Anne task and Smarties Tasks. Although his academic achievements were excellent, he had trouble making friends at school because he only spoke about what interested him and did not share interests with his classmates. He also experienced considerable difficulties understanding his and others' emotions.

We explained the purpose of our study to the par-

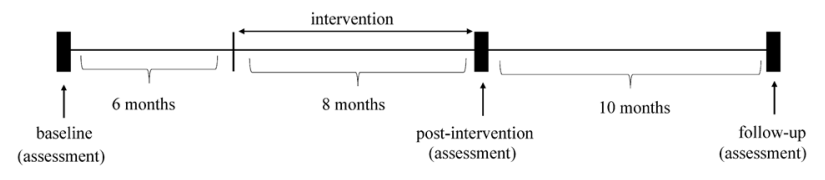

Fig. 1 The Overall Course of the Assessment and Intervention

ticipant and his guardian. Subsequently, we obtained consent for him to participate in the study and to present our findings. The Chiba University Bioethics Review Committee approved the research [approval No. 38].

\section{Experimental Design and Procedures}

The assessments and intervention are depicted in Fig. 1. The changes were assessed by comparing the differences in the participant's scores for the ToM tasks, IRI, and conversational analysis at baseline, post-intervention, and follow-up. The baseline data were collected with an unfamiliar conversational partner before starting the intervention when the participant was nine years, six months old. Subsequently, the post-intervention data were collected when he was ten years, eight months old. Finally, data were collected approximately ten months after the post-intervention to assess generalization and maintenance when the participant was 11 years, six months old.

\section{Intervention}

The participant attended 10 sessions of emotional and conversational training over an eight-month period. The aim of this intervention was to help him recognize his own emotions and understand the difference between his emotions and those of others. The author conducted the intervention in a session room in the educational department of the affiliated university. Each training session lasted approximately 40 minutes. The intervention focused on emotional training and was based on the CAT-kit Cognitive Affective Training (Callesen, Nielsen, \& Attwood, 2008) during the first five sessions. During these sessions, he related what had happened during the week, including the day before the session, how he felt about those events, why he felt that way, and what he thought his family and other people around him felt. During these discussions, he found an appropriate expression card or emotional word card from those he was using and presented it. The discussion focused on the emotional differences between him and others 
such as how his feelings may have differed from those around him. The participant reviewed emotions in his daily life, discussed questions about friendships, and learned PT skills during these sessions.

The purpose of the program from sessions six to 10 was to learn conversational skills. The program's mission was to become a conversation master. We utilized part of behavioral skills training to design the program. The content included discussions about what a conversation was, what to be aware of when talking, what is important in conversations, and what other people in conversations may feel. The program employed a form of behavioral skills training that included components such as instruction, modeling, and monitoring. In the instruction component, we explained what individuals need to do in a conversation, including looking at the other's face and nodding during the conversation. During modeling, the author presented some excellent examples of a conversation and checked them with the participant. Thereafter, he practiced these examples of the conversation. As feedback, we recorded the conversation scenes in advance by video camera to watch with him later. By reflecting on our conversation, we aimed to establish the necessary skills for conversation. When the participant looked back on the conversation scenes, he concurred that he should have been careful in those conversations. We also checked each conversation recording and discussed aspects such as when conversations are necessary and how others feel when talking. Each time one task was completed, the mission was completed and scored.

\section{Assessments}

Three dependent variables, namely, the ToM tasks, the IRI score, and conversational analysis were employed to examine the conversational changes before and after the intervention.

ToM Tasks. To test ToM skills, we conducted the Sally-Anne task (Baron-Cohen et al., 1985) and Smarties Task (Perner, Leekman, \& Wimmer, 1987). The Sally-Anne task is the most common variation of the unexpected location false belief task. The Smarties Task is a task that explores whether children are able to reflect on their own mental states correctly.

IRI. The Japanese version of the Multidimensional Empathy Scale for Children (MESC-J: Hasegawa, Horiuchi, Suzuki, Sado, \& Sakamoto, 2009) was uti- lized to explore the participant's empathy and PT skills. This scale, which is based on Davis' (1983) IRI scale, measures four dimensions of empathy: empathic concern (EC), perspective-taking (PT), personal distress (PD), and fantasy (FS). The IRI is suitable for examining the development of empathy, where role acquisition and other-oriented empathy occur later in childhood (Hoffman, 2000).

Hasegawa et al. (2009) revealed the average IRI scores of fourth grade boys with typical development were as follows: $\mathrm{EC}=21.62$ (SD 5.17), $\mathrm{PT}=29.59$ (7.34), $\mathrm{PD}=17.73$ (6.31), and $\mathrm{FS}=19.39$ (6.63). One year later, the average scores of the fifth grade children were as follows: $\mathrm{EC}=22.89$ (5.47), $\mathrm{PT}=31.73$ (6.38), $\mathrm{PD}=18.66$ (5.89), and FS=20.21 (7.15). The results of the assessment of fourth graders demonstrated a significant correlation between EC and PT, but relatively low correlation coefficients between $\mathrm{PD}$ and the other subscales. In the fifth-grade results, the correlation between PT and PD was not significant. Accordingly, in this study, we focused on the PT score to test the effect of the intervention and also examined the change of the EC score, which Hasegawa et al. (2009) revealed was correlated with PT.

Conversational Analyses. All conversation data were collected in a one-to-one, free-talk setting in which the participant spoke with unfamiliar conversational partners. In order to evaluate the effect of this intervention, which focused on PT ability objectively, a conversation was conducted with unfamiliar individuals who had never participated in the intervention to confirm whether the participant could utilize PT ability. The partners were undergraduate and graduate female students who were majoring in special needs education. They did not know the purpose of the experiment. We instructed the participant to talk freely with an adult whom he had met for the first time. Each conversation lasted for approximately 20 minutes. We assessed the participant's discourse abilities using two methods in the free-talk setting. In the conversation analysis, we first employed TagerFlusberg and Anderson's (1991) method to verify the responsiveness and adjacency to the previous conversation and second, we used de Villiers et al.s (2007) method to evaluate the change in pragmatic characteristics in the conversation by objective indicators.

1) Adjacency of Conversation. Each conversation was recorded using an IC recorder and all recorded voice data were transcribed and analyzed. We consid- 
ered one sentence with a period (.) as an utterance. Ohkubo (1973, p.71) noted, "One utterance ends with a verb or a final particle at the end of the sentence. Some spaces may have between next utterance. At the end of the sentence, the intonation is down (the question format goes up), or the voice also disappears." In relation to nodding, we referred to Yoshida (2013) and decided to limit this to lexical responses and not include non-verbal forms.

We coded the participant's utterances at three levels for adjacency, contingency, and various categories of contingent discourse in accordance with TagerFlusberg and Anderson's (1991) method. At the first level, the participant's utterances were coded for adjacency to examine their relationships to prior adult utterances. Tager-Flusberg and Anderson (1991, p. 1126-1127) stated that in this context, "adjacent" refers to when a "child utterance follows immedi- ately after an adult utterance addressed to child" and "non-adjacent" is when a "child utterance does not follow immediately after adult utterance; may follow a child utterance, after an adult utterance with intervening pause, vocalizations, or an adult utterance not addressed to child."

Only adjacent utterances were coded at the second level, based on their relation to the topic of the previous adult utterance. Child utterances were coded as contingent in instances where the "child utterance maintains topic of prior adult utterance without being a simple imitation" (Tager-Flusberg \& Anderson, 1991). The following is an example of contingent:

Adult: This season, you will be able to play in the playground during lunch break.

Child: Many classes, including our class often play with dodgeballs.

On the contrary, child utterances were coded as

Table 1 The Rate of Various Categories of Contingent Discourse from Baseline to Follow-up (\%)

\begin{tabular}{|c|c|c|c|c|c|}
\hline & Definition & Baseline & $\begin{array}{c}\text { Post- } \\
\text { intervention }\end{array}$ & $\begin{array}{l}\text { Follow- } \\
\text { up }\end{array}$ & \\
\hline \multicolumn{6}{|c|}{ No new information } \\
\hline yes/no & one word yes/no (or equivalent) responses. & 13.08 & 38.55 & 21.88 & $\begin{array}{l}p<.01 \text { (baseline }<\text { post- } \\
\text { intervention) }\end{array}$ \\
\hline routine & $\begin{array}{l}\text { includes standard social routines (e.g., thank you, } \\
\text { good night), verbal games, songs, TV talk, etc. }\end{array}$ & 0.93 & 1.20 & 1.88 & \\
\hline recode & $\begin{array}{l}\text { repetition of prior adult utterance with some } \\
\text { alteration in form; however, no additions or } \\
\text { changes in meaning. }\end{array}$ & 1.87 & 2.41 & 0.63 & \\
\hline self-recode & $\begin{array}{l}\text { repetition of child's own prior utterance after } \\
\text { intervening adult acknowledment, with alterations } \\
\text { in form but not in meaning. }\end{array}$ & 0.00 & 0.00 & 0.00 & \\
\hline wh-response & $\begin{array}{l}\text { simple noun phrase response to adult test wh- } \\
\text { questions. }\end{array}$ & 5.61 & 16.27 & 10.63 & $\begin{array}{l}p<.05 \text { (baseline }<\text { post- } \\
\text { intervention) }\end{array}$ \\
\hline Total & & 21.50 & 58.43 & 35.00 & \\
\hline \multicolumn{6}{|l|}{ New information } \\
\hline expansion & $\begin{array}{l}\text { adds information to topic and content of prior } \\
\text { adult utterance. }\end{array}$ & 19.63 & 13.86 & 11.88 & \\
\hline self-expansion & $\begin{array}{l}\text { adds information to topic of child's own prior } \\
\text { utterance after intervening adult acknowledgement. }\end{array}$ & 51.40 & 15.66 & 35.00 & $\begin{array}{l}p<.01 \\
\quad(\text { post-intervention }<\text { baseline) } \\
\quad(\text { post-intervention }<\text { follow-up) }\end{array}$ \\
\hline alternative & $\begin{array}{l}\text { adds information by opposing some aspect of } \\
\text { content of adult prior utterance. }\end{array}$ & 3.74 & 7.23 & 5.00 & \\
\hline expatiation & $\begin{array}{l}\text { adds information to topic of prior adult utterance } \\
\text { and introduces new related topic. }\end{array}$ & 3.74 & 4.82 & 13.13 & $p<.05$ (baseline $<$ follow-up) \\
\hline Total & & 78.50 & 41.57 & 65.00 & \\
\hline
\end{tabular}

Note. The definitions are from Tager-Flusberg and Anderson (1991) 
non-contingent when "child utterance does not relate to topic of prior adult utterance" (Tager-Flusberg \& Anderson, 1991).

At the third level, all contingent utterances coded at the second level were further coded to distinguish the different ways in which the participant maintained the ongoing topic of discourse. The participant's contingent utterances were classified into nine categories. When the child utterance did not contain new information, it was classified as no new information. The following categories were used: yes/no, routine, recode, self-recode, and wh-response. When the child utterance contained new information, it was classified as new information. The following categories were used: expansion, self-expansion, alternation, and expatiation. These definitions are presented in Table 1.

We extracted the participant's utterances immediately after the adult's speech and coded them according to the classification. In relation to the first level adjacency, we calculated the proportion of utterances in each classification, with the participant's total utterances as the denominator. With regard to the relevance of the second level, the percentage of each was calculated, with the number of utterances with adjacency as the denominator. These first and second level analyses allowed us to measure the relationship to a prior adult utterance and investigate the participant's conversational competence in maintaining a topic of discourse.

In relation to the third level answers, the percentage of each was calculated, with the number of contingent utterances as the denominator. Furthermore, we divided the nine categories into answers that had no new information and answers that revealed new information. We conducted the Kruskal-Wallis test for the third level items. Furthermore, we investigated the child's conversational competence in developing a topic of discourse. Raters' agreement was calculated for $29.98 \%$ or $131 / 437$ of the total conversational data. The raters were graduate students who were unaware of the purpose of this study. The interrater reliability was calculated by dividing the total number of agreements by the total number of agreements plus disagreements and multiplying this by 100. The mean inter-rater agreement was $90.08 \%$.

2) Pragmatic Skills. We examined the qualitative characteristics of the participant's utterances to investigate the pragmatic aspects thereof. To inves- tigate the pragmatic characteristics from baseline to follow-up, we rated all the participant's utterances by employing de Villiers et al's (2007) scale for rating conversational impairment in ASD. The scale comprises nine features that characterize the language of children with ASD: formal intonation, topic switching, terseness, pedantic speech, perseveration, pausing, disengagement from verbal context, attention to outside environment, and atypical stress selection. Each item of the scale is valued between 0 and 2 points; thus, one's score for the whole scale is between 0 and 18 points. Higher scores indicate individuals have more characteristics of ASD. Lower scores reveal individuals' language abilities for their age are close to being appropriate. As noted previously, the raters listened to $29.98 \%$ of the total conversational data to provide their scores. The total score was calculated by averaging the scores of the two raters.

\section{Social Validity}

After the intervention, we interviewed the participant and his mother to assess whether he had completed the training without suffering any distress.

\section{Results}

\section{ToM Tasks}

We conducted the ToM tasks (Sally-Anne task and Smarties Task) with him. He passed both tasks at post-intervention.

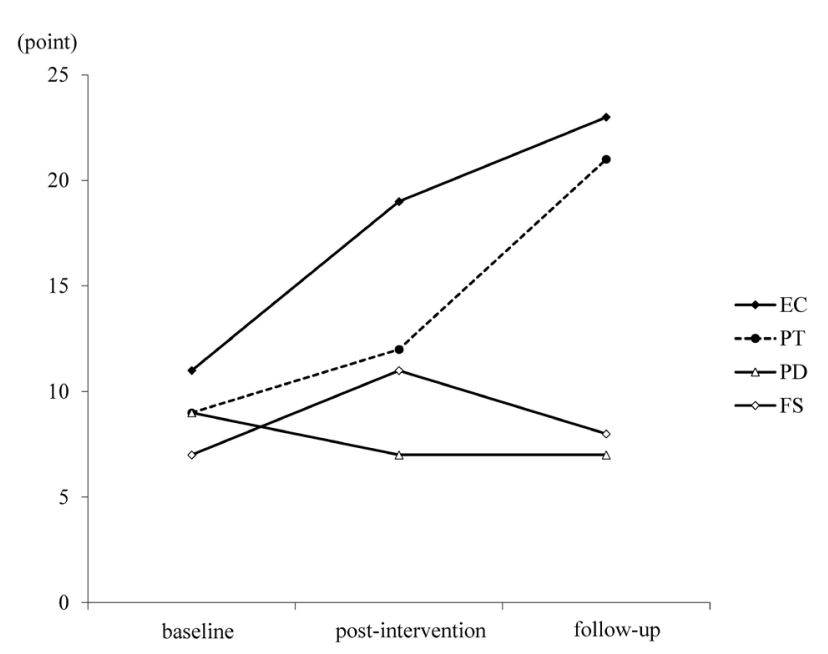

Fig. 2 The Score of MESC-J from Baseline to Follow-up

Note. MESC-J=Multidimensional Empathy Scale for Children, EC=Empathy Concern, PT=PerspectiveTaking, $\mathrm{PD}=$ Personal Distress, FS=Fantasy 


\section{The Score of IRI}

We completed the MESC-J (Hasegawa et al., 2009) with the participant during each conversation session. All the scores are displayed in Fig. 2. A comparison of the baseline and post-intervention scores revealed EC increased by 8 points, from 11 to 19 , and PT increased by 3 points, from 9 to 12. PD decreased by 2 points, from 9 points at baseline to 7 points at post-intervention and follow-up. FS increased by 7 points to 11 points at post-intervention from baseline, but decreased by 11 points in the follow-up to 8 points.

\section{Conversational Analysis}

1) Adjacency of Conversation. At the first level, the results of adjacency revealed that the rate of adjacent utterances was $100 \%$ at baseline, $99.4 \%$ at postintervention, and $100 \%$ at follow-up. The rate of unintelligible utterances was $0.6 \%$ only at post-intervention. There were no non-adjacent utterances during any period. Only adjacent utterances were coded at the second level, given their relation to the topic of the previous adult utterance. The results of the analysis of the second level showed that at baseline the rate of contingent utterances and non-contingent utterances was $97.27 \%$ and $2.3 \%$, respectively. The rate of contingent utterances was $100 \%$ at both the postintervention and follow-up.

The results of the third level are displayed in Table 1. In the third level, the participant's utterances were coded into various categories of contingent discourse that either added or did not add new information. In relation to no new information, there were significant differences in the percentages of yes/no $(p<.01)$ and wh-responses $(p<.05)$ between baseline and postintervention. This indicated that there were many instances in which the other party's question was answered simply with yes/no or with words only.

An example of a conversation at baseline is as follows:

Adult: What do you play at school?

Child: Getting rid of insects.

Adult: Anything else?

Child: The other important thing.

Adult: What's this?

Child: Finding ant nest.

On the contrary, an example of a conversation in the post-intervention is as follows:

Adult: What were you doing at lunch break?
Child: Reading a book.

Adult: What kind of books did you read?

Child: Various.

Adult: Were they interesting?

Child: Yes.

The percentages of yes/no and wh-responses in the post-intervention was higher than that at baseline. At baseline, the frequency of actually answering the partner's question was low and not just that of answering with only words or yes/no.

In relation to new information, the percentage of self-expansion was significantly lower $(p<.01)$ postintervention than at baseline. This was often demonstrated in the baseline conversation and revealed how he continued to talk about his own interests. An example of a conversation at baseline follows:

Child: $50 \%$ of the people in this school are dangerous.

Adult: Wow! There are many dangerous people.

Child: Always fighting.

Adult: Well, I see.

Child: The principal says that he should be more gentle.

Adult: Yeah. A lot of fights.

Child: And ... getting rid of insects

Adult: Yes? Getting rid of insects? Yes.

Child: I walk around school grounds and often get rid of insects.

Subsequently, the child continued talking about insect extermination.

In the post-intervention conversation, the percentage of self-expansion was significantly lower than that at baseline. An example of a conversation at post-intervention follows:

Child: I like thinking about how it works in science.

Adult: Wow! Great!

Child: For example, how to attach a light bulb or around a gear.

Adult: Yes, I see.

The participant later answered his partner's questions, but did not stick to the topic.

Expatiation was significantly higher at follow-up than at baseline $(p<.05)$. This involves developing a story while simultaneously incorporating other stories. An example of such follows:

Adult: There are ant nests everywhere.

Child: It takes time to find a queen ant. It can take over a year.

As demonstrated, at baseline, although the partici- 
pant answered his partner's questions sometimes, he rarely responded to his partner's topics.

An example of a conversation at the follow-up is as follows:

Child: The cleaning committee collects garbage in garbage bags.

Adult: That's an important job.

Child: The amount of garbage collected in one week is one bag of the garbage bags that are distributed.

Adult: Yeah, do you collect from various places?

Child: It's okay because there's only one trash can in the toilet.

Adult: That's a tough job.

Child: Maybe, there are 200 people.

In the follow-up, the participant often elaborated on his partner's utterances.

However, overall, the frequency of new information between the three assessments was not significant.

2) Pragmatic Skills. Nine scales were employed to measure the pragmatic skills (Table 2). Overall, the post-intervention and follow-up scores were lower in comparison to those at baseline. Furthermore, the ASD characteristics related to pragmatic skills decreased. Topic switching and perseveration were prominent at baseline, but subsequently disappeared. At baseline, it was remarkable that the participant spoke about a ghost story he was very interested in at that time. However, the topic gradually changed to that of getting rid of insects and later he focused on the ghost story again.

The scores of formal intonation, terseness, pedantic speech, and atypical stress selection did not change from baseline to follow-up, and remained high. These scores were mainly based on the impression of speech. The changes in conversational skills from baseline to follow-up are presented in Table 3 .

\section{Social Validity}

In the interview conducted with the participant and his mother after the intervention, they both stated that he had not experienced the intervention as distressful.

\section{Discussion}

The primary purpose of this study was to examine the effectiveness of an intervention focused on the PT ability of a child with ASD. With regard to the first and second hypotheses, the results revealed differ-

Table 2 The Score of Pragmatic Skill from Baseline to Follow-up

\begin{tabular}{|c|c|c|c|c|}
\hline & Baseline & $\begin{array}{l}\text { Post- } \\
\text { intervention }\end{array}$ & $\begin{array}{l}\text { Follow- } \\
\text { up }\end{array}$ & State of the participant \\
\hline 1 Formal Intonation & 1 & 1 & 0.5 & \\
\hline 2 Topic Switching & 1 & 0 & 0 & $\begin{array}{l}\text { He frequently switched conversation topics in the } \\
\text { baseline conversation. For example he switched from } \\
\text { a ghost story to stories about getting insects, and } \\
\text { then to another ghost story. }\end{array}$ \\
\hline 3 Terse & 1 & 2 & 1 & $\begin{array}{l}\text { He often answered questions very briefly, using yes/ no } \\
\text { or simple words. This was especially seen in the post- } \\
\text { intervention conversation. }\end{array}$ \\
\hline 4 Pedantic Speech & 2 & 1 & 0.5 & $\begin{array}{l}\text { At baseline he often spoke pedantically. After the } \\
\text { intervention, he was less likely to speak pedantically. }\end{array}$ \\
\hline 5 Perseveration & 1.5 & 0 & 0 & $\begin{array}{l}\text { Perseverating to topics of his interst (e.g., about insects } \\
\text { and ghosts) was prevalent at baseline. He continued } \\
\text { to talk about his favorite topics without answering } \\
\text { adult questions. }\end{array}$ \\
\hline 6 Pausing & 0.5 & 0 & 0 & \\
\hline 7 Disengagement from Verbal Content & 0 & 0 & 0 & \\
\hline 8 Attention to Outside Enviroment & 0 & 0.5 & 0 & \\
\hline 9 Atypical Stress Selection & 1 & 0.5 & 0.5 & \\
\hline Total & 8 & 5 & 2.5 & \\
\hline
\end{tabular}

Note. The scores assessed the pragmatic skill uniqued to people with ASD. A lower score indicated less features. 
Table 3 Changes in Conversational Skills from Baseline to Follow-up

\begin{tabular}{|c|c|c|}
\hline & \multicolumn{2}{|c|}{ Changes in conversational skills } \\
\hline & Conversational analysis & Pragmatic skills \\
\hline Baseline & $\begin{array}{l}\text { The rate of self-expansion was high. He always spoke } \\
\text { to add some information to the topic of his own prior } \\
\text { utterance. }\end{array}$ & $\begin{array}{l}\text { He often spoke pedantically. He frequently switched } \\
\text { conversation topics in the conversation and continued } \\
\text { to talk about his favorite topics without answering adult } \\
\text { questions. Perseverating on topics of his interest was } \\
\text { prevalent. }\end{array}$ \\
\hline $\begin{array}{l}\text { Post- } \\
\text { intervention }\end{array}$ & $\begin{array}{l}\text { He often answered questions using yes/no or simple } \\
\text { noun phrases. The rate of expansion and that of self- } \\
\text { expansion was about the same. He was able to speak } \\
\text { using information on the topic and content of prior adult } \\
\text { utterance. }\end{array}$ & $\begin{array}{l}\text { He often answered questions very briefly, using yes/no or } \\
\text { simple words. He was less likely to speak pedantically. }\end{array}$ \\
\hline Follow-up & $\begin{array}{l}\text { The rate of expatiation was higher than that at other times. } \\
\text { He was able to proceed with the conversation using } \\
\text { information on the topic of prior adult utterance and } \\
\text { introduce new related topics. }\end{array}$ & His speaking was less pedantic. \\
\hline
\end{tabular}

ences between baseline and post-intervention in the participant's ToM and IRI scores. He passed the ToM tasks at post-intervention. At post-intervention, his EC was 19, which was approximately the same as the mean score for groups of typically developing boys (21.62; Hasegawa et al., 2009). However, at baseline, his EC was 11. Both ToM and EC are relevant cognitive aspects of empathy. Furthermore, ToM and cognitive empathy are often used synonymously (e.g., Baron-Cohen \& Wheelwright, 2004; Davis, 1983). Aspects of cognition in empathy play a role in understanding others' feelings, intentions, and motivations. These functions of empathy may be related to the increase in the EC score, with the improvement in discourse ability. On the contrary, the participant's PT score did not increase at post-intervention. Through the intervention that focused on PT ability, his emotional cognition of himself and others improved. This was sufficient for him to acquire PT ability. Davis and Franzoi (1991) noted that PT and EC scores change increasingly during adolescence. As the participant's PT score increased at follow-up, we predict that his PT ability is likely to improve in the future.

Our third hypothesis was that our intervention would lead to a higher rate of adjacent utterances and utterances about new information compared to those at baseline. The results revealed that although there were positive changes in the participant's discourse ability over time, these changes did not support the hypothesis with regard to the addition of new infor- mation. There were no significant differences in the rates of new information and no new information after the intervention. At the baseline, as he had more one-sided utterances in many conversations, the frequency of new information was high. On the contrary, particularly at post-intervention, he began to listen to his partner and anything related to what his partner had said. He answered his partner's questions using yes/no and provided answers to questions more frequently. Thus, it is probable that his utterances did not only lead to an increase in new information. This suggested that when conversing, a good balance between no new information and new information is desirable.

In relation to the change in topic of conversation, the results showed some differences after the intervention. At baseline, the participant often persisted with his favorite topics and kept talking without responding to the other person's questions, thus displaying a high rate of self-expansion. During conversation, he sometimes switched topics quickly, without considering others' perspectives. He also did not understand the necessity of taking turns when conversing. At post-intervention, the characteristics of his conversation differed from those at baseline; for example, he did not keep talking about his favorite topics. Significantly, the results of the intervention showed a higher rate of yes/no responses than those at baseline and follow-up. Although he often responded with yes or no, he was able to answer or give explanations in response to others' questions. At 
follow-up, the frequency of expatiation was the highest. He was able to add some information about his favorite topics and answer questions from others. This showed that he was able to maintain a conversation by considering the information and knowledge the other person imparted. Tager-Flusberg and Anderson (1991) revealed that the use of topicrelated discourse that adds new information increases as children's language ability develops. Therefore, the increase of expatiation in the participant's utterances showed improvement in his discourse ability. We are of the view that his changes in discourse ability were influenced not only by age, but also by various effects of the intervention. In addition, utilizing video while conversing about daily life proved to be effective to confirm his conversation skills. Koegel, Ashbaugh, Navab, and Koegel (2016) revealed that three adults with ASD improved their verbal expression of empathetic statements and empathetic questions during conversation following a video-feedback intervention. They further found that all the participants' empathic listening statements increased during social conversation and their communication abilities improved. Furthermore, as the video-feedback intervention could confirm the participant's manner of conversing, we demonstrated that it was effective in training conversation skills. Therefore, one may speculate that he learned the importance of listening to the other's information in the conversation scenes.

The fourth hypothesis was supported. Some studies reported that individuals with ASD have characteristics of speech such as topic movement, persisting with a favorite topic, and topic maintenance (Capps et al., 1998; Dobbinson et al., 1998; Inada \& Kamio, 2007). At the beginning of the intervention, the participant had difficulty in communicating with others, particularly in topic maintenance and listening to others talk. We conducted this intervention by employing situations and emotions in his daily life. Therefore, our intervention led to an improvement in the participant's IRI score and conversation quality. Individuals with ASD may learn to communicate with others more easily through interventions designed to help them recognize and understand the differences between their emotions and those of others.

In conclusion, our study showed that the intervention, which was designed to focus on emotion, had some effects on improving the PT ability of a child with ASD. However, this study also had some limita- tions. It was a case study, with only one participant with ASD; therefore, it is unclear whether the findings can be generalized as a beneficial intervention for children with ASD. It is recommended that future studies employ a group setting of children and adolescents with ASD and thus, reveal the effects of the intervention on their conversational skills.

\section{Note}

The contents of the conversation examples in the text were slightly modified to avoid identifying individuals.

\section{Acknowledgment}

The author is grateful to the boy and his family for participate and cooperate in this study. This work was supported by JSPS KAKENHI Grant Number JP 25780540 . We wish to thank the anonymous reviewers for their many fruitful opinions.

\section{Conflicts of Interest Statement}

The author declares that the research was conducted in the absence of any relationship that could be construed as a potential conflict of interest.

\section{References}

Aichhorn, M., Perner, J., Kronbichler, M., Staffem, W., \& Ladurner, G. (2006) Do visual perspective tasks need theory of mind? NeuroImage, 30, 1059-1068.

Baron-Cohen, S., Leslie, A. M., \& Frith, U. (1985) Does the autistic child have a "theory of mind"? Cognition, 21, 37-46.

Baron-Cohen, S. \& Wheelwright, S. (2004) The empathy quotient: An investigation of adults with Asperger syndrome or high functioning autism, and normal sex differences. Journal of Autism and Developmental Disorders, 34, 163-175.

Beck, L., Kumschick, I. R., Eid, M., \& Klann-Delius, G. (2012) Relationship between language competence and emotional competence in middle childhood. Emotion (Washington, D.C.), 12, 503-514.

Callesen, K., Nielsen, A. M., \& Attwood, T. (2008) The CAT-kit: Cognitive affective training. Future Horizons.

Capps, L., Kehres, J., \& Sigman, M. (1998) Conversational abilities among children with autism and children with developmental delays. Autism, 2, 325-344.

Davis, M. H. (1983) Measuring individual differences in empa- 
thy: Evidence for a multidimensional approach. Journal of Personality and Social Psychology, 44, 113-126.

Davis, M. H. \& Franzoi, S. L. (1991) Stability and change in adolescent self-consciousness and empathy. Journal of Research in Personality, 25, 70-87.

de Villiers, J., Fine, J., Ginsberg, G., Vaccarella, L., \& Szatmari, P. (2007) A scale for rating conversational impairment in autism spectrum disorder. Journal of Autism and Developmental Disorders, 37, 1375-1380.

Dobbinson, S., Perkins, M. R., \& Boucher, L. (1998) Structural patterns in conversations with a woman who has autism. Journal of Communication Disorders, 31, 113-134, quiz 133-134.

Dziobek, I., Rogers, K., Fleck, S., Bahnemann, M., Heekeren, H. R., Wolf, O. T., \& Convit, A. (2008) Dissociation of cognitive and emotional empathy in adults with Asperger syndrome using the multifaceted empathy test (MET). Journal of Autism and Developmental Disorders, 38, 464-473.

Hale, C. M. \& Tager-Flusberg, H. (2005) Social communication in children with autism: The relationship between theory of mind and discourse development. Autism, 9, 157-178.

Hamilton, A. F. de C., Brindley, R., \& Frith, U. (2009) Visual perspective taking impairment in children with autistic spectrum disorder. Cognition, 113, 37-44.

Hasegawa, M., Horiuchi, Y., Suzuki, K., Sado, M., \& Sakamoto, A. (2009) Reliability and validity of multidimensional empathy scale for children. The Japanese Journal of Personality, 17, 307-310. (in Japanese)

Hoffman, M. L. (2000) Empathy and moral development: Implications for caring and justice. Cambridge University Press, Cambridge, U. K.

Inada, N. \& Kamio, Y. (2007) Pragmatic features of speech in Asperger's disorder: Results from conversation analysis of an adult case. Japanese Journal of Child and Adolescent Psychiatry, 48, 61-74. (in Japanese)

Japanese WISC-III Publication Committee (1998) Japanese version of Wechsler Intelligence Scale for Children, 3rd edition. Nihon Bunka Kagakusha, Tokyo. (in Japanese)

Kanner, L. (1943) Autistic disturbances of affective contact. Nervous Child, 2, 217-250.

Kato, K. \& Fujino, H. (2018) Promoting "altruistic speech" for children with autism spectrum disorder (ASD) using tabletalk role playing game (TRPG). Bulletin of Tokyo Gakugei University. Division of Comprehensive Educational Science, 69, 277-284. (in Japanese)
Koegel, L. K., Ashbaugh, K., Navab, A., \& Koegel, R. L. (2016) Improving empathic communication skills in adults with autism spectrum disorder. Journal of Autism and Developmental Disorders, 46, 921-933.

LeBlanc, L. A., Coates, A. M., Daneshvar, S. D., Charlop-Christy, M. H., Morris, C., \& Lancaster, B. M. (2003) Using video modeling and reinforcement to teach perspective-taking skills to children with autism. Journal of Applied Behavior Analysis, 36, 253-257.

Nilsen, E. S. \& Fecica, A. M. (2011) A model of communicative perspective-taking for typical and atypical populations of children. Developmental Review, 31, 55-78.

Nuernberger, L. E., Ringdahl, J. E., Vargo, K. K., Crumpecker, A. C., \& Gunnarsson, K. F. (2013) Using a behavioral skills training package to teach conversation skills to young adults with autism spectrum disorders. Research in Autism Spectrum Disorders, 7, 411-417.

Ohkubo, A. (1973) The development of syntactic structures in children's speech from 3 to 6 . The Report of National Language Research Institute, 50. (in Japanese)

Palmen, A., Didden, R., \& Arts, M. (2008) Improving question asking in high-functioning adolescents with autism spectrum disorders: Effectiveness of small-group training. Autism, 12, 83-98.

Perner, J., Leekman, S., \& Wimmer, H. (1987) Three-year-olds' difficulty with false belief: The case for a conceptual deficit. British Journal of Developmental Psychology, 5, 125-137.

Rogers, K., Dziobek, I., Hassenstab, J., Wolf, O. T., \& Convit, A. (2007) Who cares? Revisiting empathy in Asperger syndrome. Journal of Autism and Developmental Disorders, 37, 709-715.

Scattone, D. (2007) Social skills interventions for children with autism. Psychology in the Schools, 44, 717-726.

Southall, C. \& Campbell, J. M. (2015) What does research say about social perspective-taking interventions for students with HFASD? Exceptional Children, 81, 194-208.

Tager-Flusberg, H. \& Anderson, M. (1991) The development of contingent discourse ability in autistic children. Journal of Child Psychology and Psychiatry, and Allied Disciplines, 32, 1123-1134.

Yoshida, E. (2013) Detecting patterns of sequences by coding scheme and transcribed utterance information: An analysis of Japanese reactive tokens as non-primary speaker's role. Proceedings of Workshop Japanese Language Corpus, 3, 435-440. (in Japanese) 